\title{
Crack Mapping on Shear-critical Reinforced Concrete Beams using an Open Source Digital Image Correlation Software
}

\author{
Suryanto, B. ${ }^{1 *}$, Tambusay, A. ${ }^{1,2}$, and Suprobo, P. $^{2}$
}

\begin{abstract}
Three reinforced concrete beams, one with no shear reinforcement and two others with shear reinforcement ratios of $0.4 \%$ and $1.1 \%$, were tested to investigate the influence of stirrup spacing on the mode of failure, overall strength and ductility. The results show that the beam reinforced with closely-spaced shear reinforcement failed in a ductile manner, whereas the other two beams with large stirrup spacing and no stirrup exhibited only a small measure of ductility and failed in a brittle manner. The importance of the provisions of maximum spacing is highlighted to ensure adequate anchorage for the stirrups and prevent a premature shear failure to occur. The application of a non-contact monitoring system employing the open source digital image correlation software Ncorr, an ordinary digital camera and a smartphone is demonstrated to provide a visualization of the cracking process throughout the load history.
\end{abstract}

Keywords: Brittle; crack mapping; diagonal crack; Ncorr; shear failure; strain field.

\section{Introduction}

Reinforced concrete members are generally designed to exhibit ductile flexural failure. This is to ensure that as these members are overloaded, they will exhibit visible signs of distress in the form of, for example, extensive cracking or large deflection. These signs are, from an engineering point of view, very useful as they can serve as an early warning before failure ultimately takes place [1]. Apart from flexural failure, structural members can also fail in shear, which is far more brittle [2]. Shear failure can even occur with no prior warning such as in members with inadequate amount or no shear reinforcement [3-5].

When designing a reinforced concrete beam, practising engineers would generally have to follow the requirements set out by national design specification, which in Indonesia is SNI2847:2013 [6], drafted largely based on ACI 318M-11 [7]. When undertaking shear design, this generally involves the calculation of the shear capacity provided by the concrete, $V_{c}$, and the contribution provided by the shear reinforcement, $V_{s}$, as per SNI 2847:2013 clauses 11.2.2.1 and 11.4.7 [6]. Engineers would also need to comply with provisions for maximum spacing and minimum shear reinforcement set out, respectively, in clauses 11.4.5 and 11.4.6.

${ }^{1}$ Institute for Infrastructure and Environment, School of Energy, Geoscience, Infrastructure and Society, Heriot-Watt University, Edinburgh, UNITED KINGDOM.

${ }^{2}$ Department of Civil Engineering, Sepuluh Nopember Institute of Technology, Surabaya, INDONESIA.

*Corresponding author; e-mail: b.suryanto@hw.ac.uk

Note: Discussion is expected before November, $1^{\text {st }} 2017$, and will be published in the "Civil Engineering Dimension", volume 20, number 1, March 2018.

Received 10 June 2017; revised 03 August 2017; accepted 14 August 2017.
It is worth mentioning that most of the shear design equations presented in this specification are of empirical in nature and do not necessarily have a physical significance. However, it is of importance that an engineer understands the assumptions behind the equations and follows the whole requirements presented in clause 11 with care, even if additional measures are taken at the end to ensure safety.

In this paper, the response of a reinforced concrete beam specifically designed to be non-compliant to SNI 2847:2013 clause 11.4.5 (maximum stirrup spacing) [6] is presented, along with the response of two geometrically identical beams containing no and closely-spaced shear reinforcement. The work aims to provide practising engineers with an appreciation of the significance of bar spacing check when undertaking shear design. To aid interpretation, a non-contact strain measurement system employing the open source digital image correlation (DIC) software, Ncorr, [8] was used to provide a visualization of the formation and propagation of cracks throughout the loading history, from initial cracking to failure. The system is relatively easy to setup, it only employs an ordinary digital camera and an off-theshelf smartphone, making it attractive for use in situations where cost is prohibitive.

\section{Experimental Programme}

\section{Test Specimens}

Three reinforced concrete beams were tested under two-point loading. The schematics of the test setup, steel reinforcement layout and cross-section details are presented in Figures 1(a) and (b). The beams had a rectangular cross-section with overall dimensions 
of $100 \times 150 \times 2000 \mathrm{~mm}^{3}$. The first beam, hereafter referred to as Beam B1, was reinforced with two 10 $\mathrm{mm}$ tension bars (denoted as $2 \mathrm{H} 10$ in Figure 1(b); in this labelling system, the prefix refers to bar number, $\mathrm{H}$ refers to Grade B500B ribbed reinforcing bar to BS 8666:2005 [9] and BS 4449:2005 [10], and the suffix refers to bar diameter in $\mathrm{mm}$ ). The other two beams, referred to as Beams B2 and B3, were reinforced with four bars: two $10 \mathrm{~mm}$ tension bars (2H10) and two $8 \mathrm{~mm}$ compression bars (2H8). Beams B2 and B3 had $8 \mathrm{~mm}$ transverse reinforcement in the form of rectangular closed stirrups. In Beam B2, the stirrups were arranged at $250 \mathrm{~mm}$ centres, corresponding to a reinforcement ratio of $0.4 \%$. This is denoted as H8-250 in Figure 1(b). In Beam B3, the stirrups were arranged at $90 \mathrm{~mm}$ centres (equivalent to a reinforcement ratio of $1.1 \%$ ) over the shear span and at $175 \mathrm{~mm}$ centres over the central span (see Figure 1(b)).

\section{Materials and Fabrication}

The mix proportions used to produce the beam are presented in Table 1 . The concrete mix had a water/ cement ratio of 0.45 and used ordinary Portland cement Grade 52.5, referred to as CEM I 52.5N in BS EN197-1:2011 [11]. A summary of the concrete compressive strength obtained in accordance to BS EN 12390-3:2009 [12] is presented in Table 2.

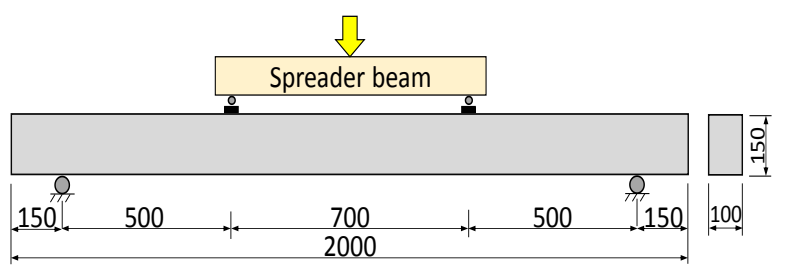

(a)

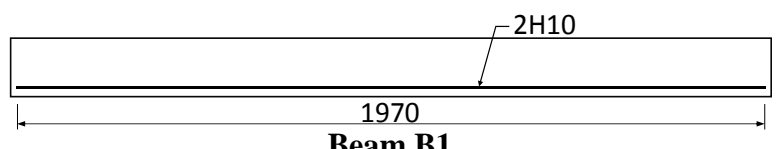

Beam B1

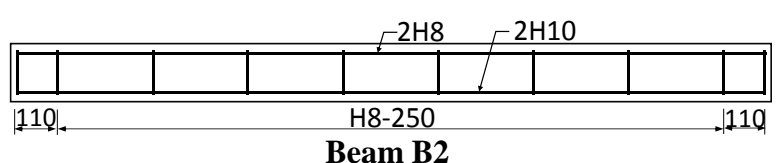

Beam B2

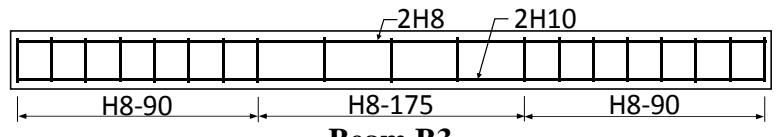

$\underline{\text { Beam B3 }}$

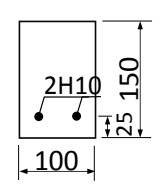

Beam B1

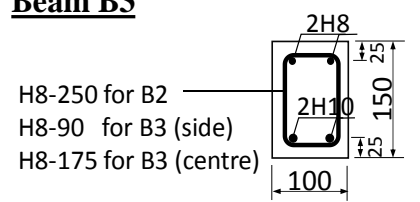

Beams B2 and B3 (b)

Figure 1. (a) Schematic of Test Setup; and (b) Elevation and Cross-section Details (all dimensions in $\mathrm{mm}$ ).
Table 1. Summary of Concrete Mix

\begin{tabular}{cccccc}
\hline w/c & $\begin{array}{c}\text { CEM I } \\
\mathrm{kg} / \mathrm{m}^{3}\end{array}$ & $\begin{array}{c}20 \mathrm{~mm} \\
\mathrm{~kg} / \mathrm{m}^{3}\end{array}$ & $\begin{array}{c}10 \mathrm{~mm} \\
\mathrm{~kg} / \mathrm{m}^{3}\end{array}$ & $\begin{array}{c}\text { Fine }(<4 \mathrm{~mm}) \\
\mathrm{kg} / \mathrm{m}^{3}\end{array}$ & $\begin{array}{c}\mathrm{Pl} \\
\mathrm{kg} / \mathrm{m}^{3}\end{array}$ \\
\hline 0.45 & 444 & 790 & 395 & 593 & 4.2 \\
\hline
\end{tabular}

Notes: $20 \mathrm{~mm}$ and 10mm: a graded crushed granite; Pl: medium range water reducer (SikaPlast 15RM).

Table 2. Summary of 28-day Compressive Strength Obtained from $100 \mathrm{~mm}$ Cubes.

\begin{tabular}{cccc}
\hline Beam & $\begin{array}{c}\text { Mean } \\
\mathrm{MPa}\end{array}$ & $\begin{array}{c}\text { SD } \\
\mathrm{MPa}\end{array}$ & $\begin{array}{c}\mathrm{CoV} \\
\%\end{array}$ \\
\hline B1 & 49.8 & 3.9 & 7.8 \\
B2 & 40.7 & 0.7 & 1.8 \\
B3 & 42.6 & 2.0 & 4.7 \\
\hline
\end{tabular}

Table 3. Properties of the Reinforcing Steel

\begin{tabular}{ccccccc}
\hline $\begin{array}{c}\text { Diameter } \\
\mathrm{mm}\end{array}$ & $\begin{array}{c}\text { Area } \\
\mathrm{mm}^{2}\end{array}$ & $\begin{array}{c}f_{y} \\
\mathrm{MPa}\end{array}$ & $\begin{array}{c}f_{u} \\
\mathrm{MPa}\end{array}$ & $\begin{array}{c}E_{s} \\
\mathrm{GPa}\end{array}$ & $\begin{array}{c}\varepsilon_{s h} \\
\%\end{array}$ & $\begin{array}{c}\varepsilon_{u} \\
\%\end{array}$ \\
\hline 8 & 50.3 & 568 & 686 & 200 & 1.4 & 10.5 \\
10 & 78.5 & 593 & 723 & 200 & 1.7 & 9.5 \\
\hline
\end{tabular}

The fabrication of the test specimens was done in three batches using a 100-litre pan mixer. From each batch, one beam was cast into a pre-assembled steel mould along with three $100 \mathrm{~mm}$ cubes. The beam was then compacted using a vibrating poker, whereas the cubes were compacted into two layers on a vibrating table. Immediately after this, the top surface was trowelled smooth and then covered with polyethylene sheeting. The specimens were removed from their moulds after 24 hours and then stored in a laboratory environment until required for testing (28 days after casting). During this curing period, all specimens were regularly wetted to ensure the availability of water for hydration.

\section{Test Setup and Instrumentation}

The test arrangement and instrumentation used in the test programme are presented in Figure 2(a). Each beam was firstly inserted into a stiff reaction frame and then rest on two roller supports over a span of $1700 \mathrm{~mm}$. The beam was subjected to twopoint loads arranged symmetrically at $700 \mathrm{~mm}$ centres. At each load point, a steel plate with dimensions of $100 \times 60 \times 10$ (thick) $\mathrm{mm}$ was positioned on the top of the beam to prevent premature failure due to local crushing of the concrete during testing. Each plate was welded to a steel rod with a diameter of 30 $\mathrm{mm}$ to facilitate a point contact with a spreader beam, which was placed directly above the two rods.

The load was applied in $5 \mathrm{kN}$ increments using a 200 $\mathrm{kN}$ hand-operated hydraulic actuator reacting against the spreader beam. The applied load during testing was determined from a $100 \mathrm{kN}$ miniature load cell installed onto the head of the hydraulic actuator, whereas the central deflection was moni- 
tored using a linear variable displacement transducer (LVDT) which was positioned underneath the beam prior to testing. These two instruments were connected to a 16bit USB data acquisition system to acquire data at a rate of $1 \mathrm{~Hz}$.

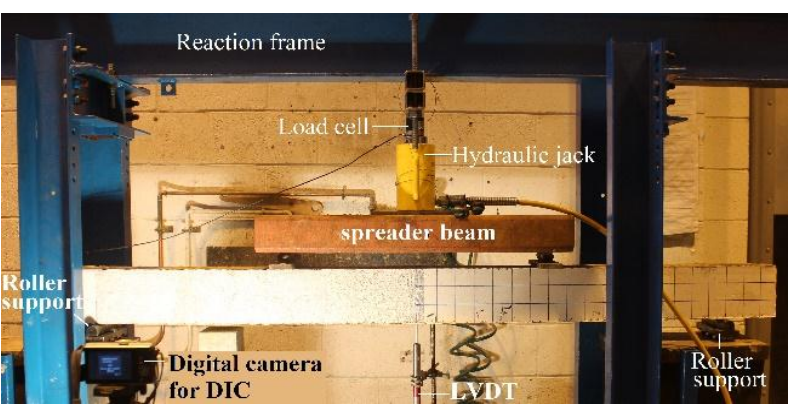

(a)

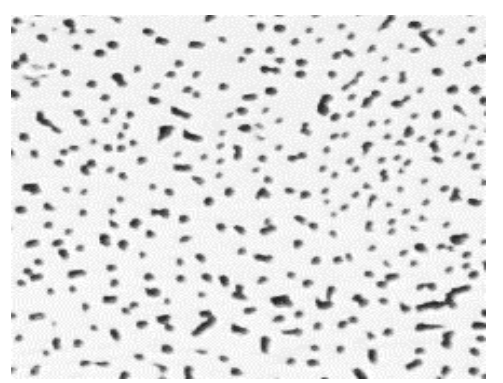

(b)

Figure 2. (a) Test Setup and Instrumentation; and (b) Enlarged View of the Random Speckled Pattern Over an Area of Approximately $50 \times 50 \mathrm{~mm}^{2}$.

Prior to testing, the front surface of the beam was coated with a thin layer of white paint. On the righthand side of this surface, gridlines were then drawn at $50 \mathrm{~mm}$ intervals to allow the exact position of concrete cracking to be determined. This manual crack mapping was done visually at load intervals of $5 \mathrm{kN}$ using colour markers.

On the left-hand side of the beam, a random speckle pattern was created using a black permanent marker, covering an area of approximately 3725×660 pixels. Figure 2(b) presents an enlarged image of the speckled pattern over an area of approximately 50 mm square. In this speckled region, automated crack mapping was done using the DIC technique and for this purpose, an 18.4MP Nikon 1 J4 mirrorless digital camera was placed on a sturdy tripod at a distance of approximately $600 \mathrm{~mm}$ from the front face of the beam. The digital camera was controlled remotely using a smart phone via the Nikon's wireless mobility utility application and the built-in Wifi feature in the camera. This remote operation was done to remove unnecessary inadvertent movement which would render measurement accuracy. Photos were then taken at intervals of $1 \mathrm{kN}$ throughout the course of the testing or at every 5 second interval once the yield capacity of the beam had been reached. These digital images were then processed using an open source 2D DIC package Ncorr version 1.2.1 [13]. The software runs in Matlab environment and comes with a user-friendly graphical interface. Figure 3(a) shows the main window of the software displaying an example of a reference image and the last current image taken after failure. The software works by creating overlapping small windows called subsets. Within each subset, the relative movement of points is tracked to generate the displacement fields, which are further processed to obtain the strain fields. For more details, the reader is referred to Blaber et al. [8]. In this work, the longitudinal strain profile, $\varepsilon x x$, was used to follow the process of crack formation during the loading process (see, for example, Figure 3(b)). The following parameters were set in the analysis: subset radius $=20$ pixels, subset spacing $=8$ pixels and strain radius $=3$ pixels.

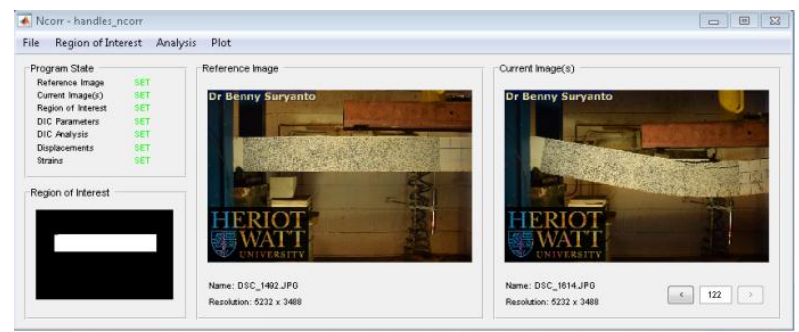

(a)

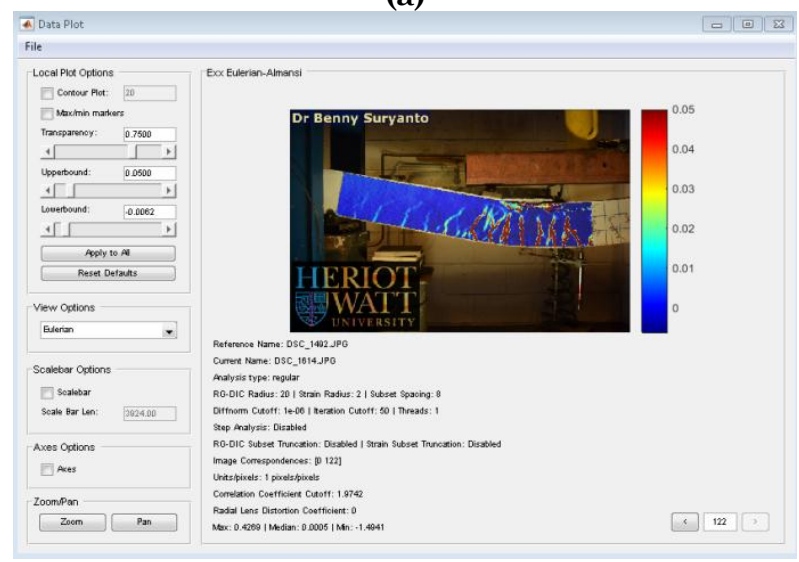

(b)

Figure 3. (a) Ncorr Main Terminal; and (b) Example Plot of Longitudinal Strain.

\section{Results and discussion}

\section{Load-deflection Relationship and Failure Crack Pattern}

The load-deflection responses exhibited by each beam are presented in Figure 4. It is evident that all beams display similar initial stiffness until the load reaches approximately $5 \mathrm{kN}$ when flexural cracks start to form and the response starts to deviate from linearity. The stiffness then decreases as the deflecttion increases, but the three beams still exhibit similar response until the load reaches approxima- 
tely $35 \mathrm{kN}$. Beam B1 then displays a lower stiffness and reaches a maximum load at $35.9 \mathrm{kN}$, which is approximately $30 \%$ higher than the load predicted using the SNI shear design equation given in clause 11.2.2.1 [6]. During testing, failure was characterised by a sudden drop in load, indicating a brittle failure with no further ductility and residual strength apparent beyond the peak load. It was noted that the failure occurred right after the initiation of a diagonal crack which then caused the beam to split literally into two distinctive parts. The failure was sudden due to rapid propagation of the diagonal crack up to the loading plate and down to the top layer of the tension reinforcement, which then continued as a horizontal crack extending toward the end of the beam (see the final crack pattern of Beam B1 presented in Figure 5). The rest of the beam remained relatively straight upon unloading, implying that the beam experienced only a small measure of ductility before failure. Due to the brittle nature of shear failure, the use of shear reinforcement is clearly recommended, even in a beam with low shear demand or in members where shear reinforcement is generally not provided such as in thick slabs and footings [14].

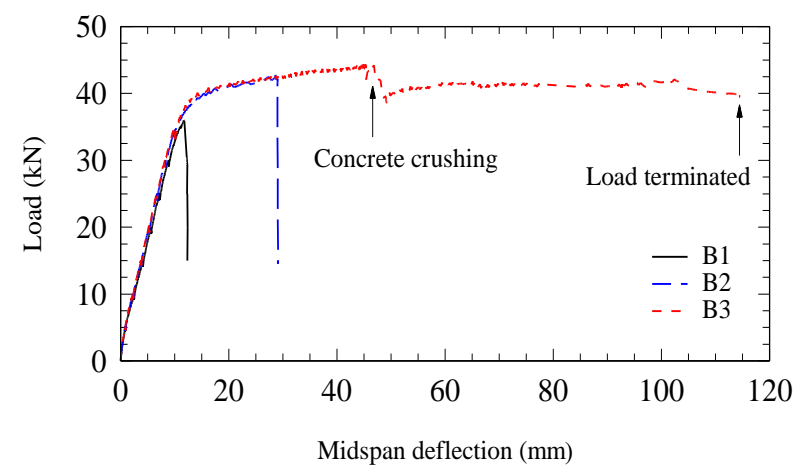

Figure 4. Load versus Mid-span Deflection

Unlike Beam B1, Beams B2 and B3 can further withstand the applied load, highlighting the important role of transverse reinforcement in preventing brittle shear failure. The flexural capacity of these beams was reached at a load of $\sim 39 \mathrm{kN}$, resulting in a sudden reduction in stiffness but the overall response is still stable. When Beam B2 reached a load of $42.4 \mathrm{kN}$, however, it failed in a notably similar manner to Beam B1. The failure was sudden and brittle, resulting from the formation of diagonal shear crack in the web region (see Beam B2's crack pattern in Figure 5). It is interesting to note that while the shear capacity of this beam is well above the flexural capacity, the spacing of the stirrups over the shear span $(250 \mathrm{~mm})$ exceeds the maximum allowable spacing permitted by current design specifications. SNI2847:2013 [6], for example, limits the spacing to $0.5 \mathrm{~d}$ (or, in this case, $62.5 \mathrm{~mm}$ ), while BS EN 1992-1-1:2004 [13] specifies the least of $0.75 \mathrm{~d}$
(93.8 $\mathrm{mm}$ ) and $600 \mathrm{~mm}$ as the maximum spacing, which in this case is $93.8 \mathrm{~mm}$. Therefore, the provided stirrup spacing in Beam B2 is clearly not compliant with these requirements and the design would have to incorporate minimum shear reinforcement as otherwise brittle failure may result. The failure of Beam B2 serves as a direct supporting evidence for this. It is hoped that the result of this non-compliant beam will provide practitioners with an appreciation of the significance of bar spacing check when undertaking shear design.

Beam B3 exhibits a large measure of ductility resulting from yielding of the tensile reinforcement. It is evident from Figure 4 that when the beam reaches a deflection of approximately $45 \mathrm{~mm}$, the load drops by about $8 \%$, from $44.5 \mathrm{kN}$ to $40.9 \mathrm{kN}$. This can be associated with crushing of $\sim 200 \mathrm{~mm}$ long concrete cover in the compressive region at the centre span. However, the beam is still able to continue carrying the load as the concrete in the remaining top of the beam (under the broken cover) is still well confined by the transverse reinforcement. This is manifest as a long horizontal portion of the load-deflection curve presented in Figure 4. Slight fluctuations in load are apparent due to progressive cracking of the concrete, which occurs concurrently with strain hardening of the longitudinal reinforcement across flexural cracks. The average load from this horizontal portion can thus be regarded as the flexural capacity of a beam with a reduced cross-section (without the top cover). Finally, the beam was fully unloaded when the deflection reached $\sim 115 \mathrm{~mm}$, resulting to a state presented in Figure 5 (denoted as B3). This was due to the hydraulic pump had reached its maximum stroke limit. It is worth mentioning that while the spacing of the stirrups over the shear span $(90 \mathrm{~mm})$ exceeds the maximum allowable spacing permitted by SNI2847:2013 [6] yet still within the maximum spacing set out in BS EN 1992-1-1:2004 [15] (see above), this did not lead to shear failure. This is due to the fact that the actual spacing of the diagonal cracks is larger than $0.5 \mathrm{~d}$. It is also worth mentioning that the deflection of the beam just before unloading was very noticeable, thereby giving ample warning before final failure. Therefore, it is clear that flexural failure is a very desirable failure mechanism and as such, engineers must always aim to achieve this type of failure when performing a design at the ultimate limit state.

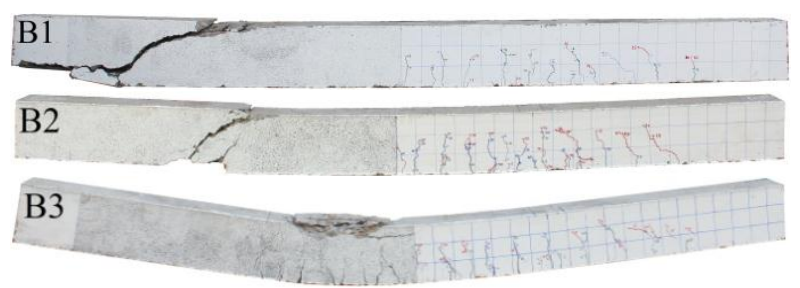

Figure 5. Crack Patterns after Failure 


\section{Crack Progression}

To provide a better insight of the beam response during testing, an example of the longitudinal strain fields obtained from Beam B2 using the proposed DIC system is presented in Figure 6(a), with the same colour range being used in all plots to facilitate direct comparison. Six stages of loading were selected, including three load levels during the postcracking response prior to yielding of the tensile reinforcement $(10 \mathrm{kN}, 20 \mathrm{kN}$ and $30 \mathrm{kN}$ ), two load levels representing the post-yielding response of the beam $(40 \mathrm{kN}, 42 \mathrm{kN})$, and the peak load.

The longitudinal strain fields of Beam B2 presented in Figure 6(a) can be used for tracking crack development at various stages of loading. From the longitudinal strain field obtained at $10 \mathrm{kN}$, for example, a very weak development of vertical strips of high strain spaced at a distance in the range $0.5 \mathrm{~d}$ to $0.75 \mathrm{~d}$ can be seen at the bottom part of the web region, which would represent flexural cracking.
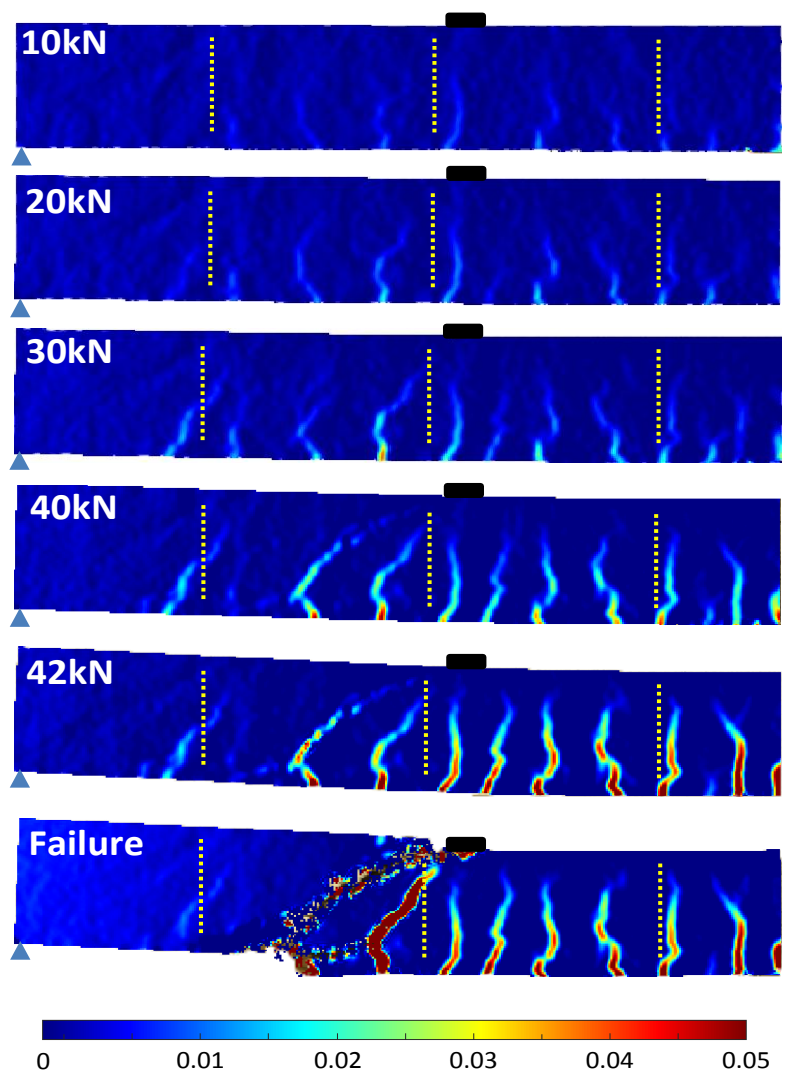

(a)

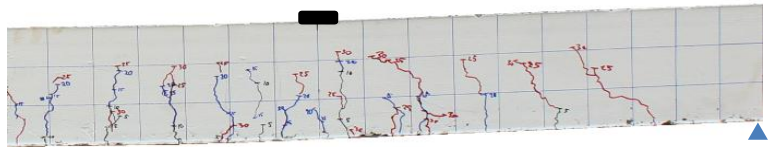

(b)

Figure 6. (a) Longitudinal Strain Maps Obtained on the Left-hand Side of the Beam, with the Approximate Locations of the Stirrups Indicated with Dotted Lines; and (b) Crack Pattern Observed on the Right-hand Side of the Beam after Failure.
It is apparent that the magnitude and length of these strips become more prominent as the load is increased to $30 \mathrm{kN}$, indicating progressive widening and propagation of existing cracks. At this stage, flexural cracks over the shear span start to exhibit a rotation at its tip, forming diagonal shear cracks which extend toward the edge of the loading plate with increasing loading. At $40 \mathrm{kN}$, it is noticed that two of these diagonal cracks open suddenly, but this does not lead to immediate failure as their propagation is ceased by the presence of the stirrup next to the point load. The same diagonal cracks can also be found on the right-hand side of the beam (see the crack pattern shown in Figure 6(b)). As the beam is further loaded to $42 \mathrm{kN}$, the pre-existing diagonal cracks continue to open along with the flexural cracks over the centre span. Given that the stirrups next to the load point are not adequately anchored into the top half of the diagonal crack region, premature shear failure eventually occurs. Overall, the results presented have clearly shown the potential of this system for crack mapping. Future work will entail further validation of the proposed technique on larger structural members under more complex loading conditions.

\section{Concluding Remarks}

Shear failure is a brittle phenomenon which can occur with no prior warning. It is thus of critical importance that practising engineers have an appreciation of the mechanisms of shear resistance and understand parameters that influence shear strength. From this limited investigation, the following can be drawn:

1. It is good practice to ensure that not only should the shear capacity be sufficiently high, but also that the spacing of shear reinforcement should be sufficiently small. This is to reduce the likelihood of any diagonal shear crack to fully develop which can lead to a brittle, catastrophic failure. Sufficiently dense stirrups are required to adequately anchor the stirrups and link the diagonal concrete struts together.

2. The provision of maximum stirrup spacing in current design specifications is normally presented in a simple form. It is a very straightforward check to perform during the design stage, but if not considered, this can result in an erroneous design which can eventually lead to an undesirable brittle failure. The response of a beam with a departure from this provision is presented to highlight the significance of the problem.

3. A simple, low-cost DIC system is introduced and shown to provide a detailed insight into the process of concrete cracking in a reinforced concrete beam. Further work will be directed toward exploiting the technique as a means of studying internal load-carrying mechanisms and monitoring the state-of-health of a structure. 


\section{Acknowledgements}

The authors wish to acknowledge financial supports from the Ministry of Research, Technology and Higher Education of the Republic of Indonesia (Grant No. 1166/D3.2/PG/2016) and from the School of Energy, Geoscience, Infrastructure and Society at Heriot-Watt University. Thanks also expressed to Danah Saraireh for her assistance in the experimental work.

\section{References}

1. Maekawa, K., Okamura, H., and Pimanmas, A., Non-linear Mechanics of Reinforced Concrete, CRC Press, London, 2003.

2. Kani, G., How Safe are Our Large Reinforced Concrete Beams?, ACI Journal Proceedings, 64(3), 1967, pp. 128-141.

3. Anderson, B.G., Rigid Frame Failures, ACI Journal, 53(1), 1957, pp. 625-636.

4. An, X., Shawky, A.A., and Maekawa, K., The Collapse Mechanism of a Subway Station during the Great Hanshin Earthquake, Cement and Concrete Composites, 19(3), 1997, pp. 241-257.

5. Suryanto, B., Morgan, R., and Han, A.L., Predicting the Response of Shear-critical Reinforced Concrete Beams using Response-2000 and SNI 2847:2013, Civil Engineering Dimension, 18(1), 2016, pp. 16-24.

6. SNI 2847:2013, Persyaratan Beton Struktural untuk Bangunan Gedung, Badan Standardisasi Nasional, Department of Public Work of Indonesia, 2013.
7. ACI 318M-11, Building Code Requirements for Structural Concrete and Commentary, American Concrete Institute, 2011.

8. Blaber, J., Adair, B., and Antoniou, A., Ncorr: Open-Source 2D Digital Image Correlation Matlab Software, Experimental Mechanics, 55(6), 2015, pp. 1105-1122.

9. BS 8666:2005, Scheduling, Dimensioning, Bending and Cutting of Steel Reinforcement for Concrete - Specification, British Standards Institution, 2008.

10. BS 4449:2005+A3:2016, Steel for the Reinforcement of Concrete - Weldable Reinforcing Steel - Bar, Coil and Decoiled Product - Specification, British Standards Institution, 2016.

11. BS EN 197-1:2011, Cement: Composition, Specifications and Conformity Criteria for Common Cements, British Standards Institution, 2011.

12. BS EN 12390-3:2009, Testing Hardened Concrete: Compressive Strength of Test Specimens, British Standards Institution, 2009.

13. Ncorr, retrieved from http://www.ncorr.com/ download/ncorr_v1_2_1.zip (accessed 20/02/2016).

14. Collins, M.P. and Kuchma, D., How Safe are Our Large, Lightly Reinforced Concrete Beams, Slabs, and Footings?, ACI Structural Journal, 96(4), 1999, pp. 482-490.

15. BS EN 1992-1-1:2004+A1:2014, Eurocode 2: Design of Concrete Structures: General Rules and Rules for Buildings, British Standards Institution, 2004. 